\title{
Attracting Future Health Workforces in Geographically Remote Regions: perspectives from current remote health professionals
}

\section{Onnis}

\begin{abstract}
Objective: The aim of this study was to identify what has previously attracted health professionals to work in geographically remote regions, to identify the incentives that managers are currently using to attract health professionals to remote regions, and to determine whether they are comparable.
\end{abstract}

Design: This article examines the data from two separate, yet complementary, research studies. The first study used qualitative methods to investigate why health professionals choose to work in geographically remote regions through current remote health workforces. The second study investigated whether information communicated through recruitment advertising contained information congruent with the themes that attracted the current remote health professionals through a content analysis of recruitment advertisements. The findings from these two studies are then compared and contrasted and Psychological Contract Theory is used to examine the implications for health service managers.
Setting: This study was conducted in northern Australia, a remote tropical setting with geographically challenging working conditions.

Results: The findings revealed that recruitment advertisements contained information comparable with the themes that had attracted health professionals to work in remote regions. Most importantly, they highlight opportunities to better align recruitment practices, and provide insight into how unrealistic expectations lead to psychological contract breaches.

Conclusions: This study found that while recruitment advertisements are using appropriate content to attract health professionals to remote regions, there is considerable scope for improvement so that attraction translates into improved retention.

Key words: recruitment; attraction; psychological contracts; retention.

\section{Leighanne Onnis \\ College of Business, Law \& Governance \\ James Cook University, \\ Cairns, Queensland, Australia. \\ Correspondence: \\ leighann.onnis@jcu.edu.au}

Many businesses and public sector organisations throughout Australia find it difficult to attract, let alone retain, staff. This 'problem' is exacerbated in remote and desert Australia, which is far removed from the attractions of the cities. [1, p. 354]

Australians living in geographically remote regions experience poorer health outcomes than the general Australian population. [2,3] In part, this is attributed to limited access to health services arising from difficulties in attracting and retaining health professionals in remote regions. [3,4] Globally, the distribution of health professionals typically sees a higher density in urban areas and a scarcity in many geographically remote regions. $[3,5]$ Furthermore, high turnover is frequently reported in many geographically remote regions. [5,6] Consequently, in regions that experience high turnover, attracting and retaining health professionals is challenging; however, some healthcare services within these regions experience reasonable levels of workforce stability. [5,7]

The literature reveals a variety of approaches to attract and retain remote health workforces. Some studies focused on the sustainability of health workforces [8-10] and others investigated place-based characteristics and the 
attractiveness of locations. [11] Some report the benefits of incentives and bonus schemes, [12] while others report that financial rewards do not lead to long-term retention. [13] Researchers have also investigated the benefits of remote placements as pathways to remote employment $[14,15]$ As a result, it appears that health professional are attracted to remote regions for a variety of reasons, and that their expectations influence job satisfaction and ultimately retention as 'one health professional's reason for leaving may be another one's reason for staying'. [10, p.49] For many health professionals, geographically remote regions are a work context with which they are unfamiliar. In fact, it is often difficult to imagine the remote work environment for those that have always lived and worked in cities. As such, recruitment processes shape their perception of employment conditions. [16] Psychological contracts develop through the employee's beliefs and perception about the employment agreement, particularly unwritten expectations and exchange obligations. [16] The perceived obligations of the employer that form a psychological contract may be transactional (e.g. financial bonuses) or relational (e.g. job security). In essence, psychological contracts describe an employee's perceived expectations and commence pre-employment.

Transactional psychological contracts are characterised by specific, short-term obligations while relational psychological contracts emphasise long-term, socio-emotional obligations. [17,12] Regardless of the type of psychological contract, reciprocity is unspecified and implicit and therefore, difficult to quantify and may be breached by managers unaware of these perceived obligations. $[17,18]$ Perceived obligations for both transactional and relational psychological contracts are formed through the information contained in recruitment advertising and develop through interactions with managers during recruitment and the early stages of employment. Where an employee perceives a psychological contract breach and/or violation, the employee's obligations to the employer are reduced or eliminated which often results in turnover. [16] Employees may accept psychological contract breaches, depending on the nature of the breach. However, once employees feel that their psychological contract has been violated, which is a more severe and emotionally charged response to an unfulfilled obligation than a breach, resignation is the most likely outcome. [16] Hence, management practices can improve retention by focusing on minimising the formation of psychological contracts that arise from unrealistic expectations.
This study was conducted in northern Australia, a remote tropical setting with challenging climatic conditions, such as cyclones and flooding, together with physical challenges, such as distance from capital cities, impassable roads and impermanent airstrips. This study included remote and very remote regions, collectively described as 'remote' for this study, in North West Queensland, Far North Queensland, Northern Territory's Top End and Western Australia's Kimberley region. Remote regions were defined using the Australian Bureau of Statistics categories for remote (RA4) and very remote (RA5), with remoteness determined as 'how far one travels to access goods and services.' [19, p.2] As Darwin is categorised as outer regional (RA3), it was excluded, unless a Darwin-based position delivered health services in an RA4 or RA5 area, such as fly-in fly-out roles. [19] While geography creates the physical environmental context, they are not isolated from the challenges that face all health professionals. [4,5] Hence, geographical remoteness contributes to health workforce challenges as it provides a complex, isolated physical environment in which to manage workforce challenges, including widespread poorer health outcomes. [5]

Based on the assumption that the incentives that attracted current remote health workforces can attract future remote health workforces; the aim of this study was to identify what has previously attracted health professionals to work in geographically remote regions, to identify the incentives that managers are currently using to attract health professionals to remote regions, and to determine whether they are comparable. This article examines the data from two separate, yet complementary, research studies that contribute to the empirical research in this field. The first study investigated why health professionals choose to work in geographically remote regions in tropical northern Australia. The second study investigated whether information communicated through recruitment advertising contained information congruent with the themes that attracted current remote health professionals. The findings from these two studies were then compared and contrasted and Psychological Contract Theory used to examine the implications for health service managers.

Approval to conduct the research was granted by the James Cook University Human Research Ethics Committee (HREC) (H5227), the Townsville Hospital and Health Service HREC (HREC113/QTHS/225) and the WA Country Health Service HREC (2013:31). 


\section{Study one}

Methods

Study one investigated the current remote health workforces' perspective through health professionals working in remote tropical northern Australia. Study one sought empirical evidence about what attracts health professionals to work in remote regions. To ensure that participants were currently working in remote northern Australia, eight organisations (two government Hospital and Health Services, two non-profit organisations, two Aboriginal Community Controlled Health Organisations, and two recruitment agencies) providing health services in remote tropical northern Australia disseminated an online questionnaire to their employees. This method ensured non-identifiable data and provided the most cost-effective method of data collection from health professionals in geographically remote locations. Qualtrics was used for the questionnaire providing a user-friendly interface for participants and a centralised data collection point, which maintained confidentiality.
The questionnaire was disseminated between January 2014 and July 2015 to 1317 remote health professionals. In total, 272 questionnaires were returned, providing a response rate of $21 \%$. Incomplete questionnaires were removed, leaving 216 questionnaires for analysis. The response rate was low; however, it was consistent with this type of research tool [20] and reasonable for this population. The Australian Medical Association reported a response rate of $13 \%$ and Rural Doctors Association of Australia reported a 13.5\% response rate for online questionnaires to health professionals in rural and remote Australia $[21,22]$ reinforcing the difficulty in achieving high response rates for this population. Study one examined responses to the free-text question from the questionnaire: Why did you choose to work in a remote region? A thematic analysis was conducted using NVIVO10 to identify the emergent themes.

Table 1: Participant Characteristics $(n=213)$

\begin{tabular}{|c|c|c|c|}
\hline VARIABLE & TOTAL \% & VARIABLE & TOTAL \% \\
\hline Region & & Gender & \\
\hline Queensland & 62.6 & Male & 16.5 \\
\hline Western Australia & 37.4 & Female & 83.5 \\
\hline No. years in current role & & No. years in remote areas & \\
\hline$<1$ year & 22 & $<1$ year & 40 \\
\hline $1-5$ years & 51 & $1-5$ years & 39 \\
\hline $6-10$ years & 21 & 6-10 years & 10 \\
\hline $11-20$ years & 3 & $11-20$ years & 9 \\
\hline$>20$ years & 3 & $>20$ years & 2 \\
\hline Age (years) & & Occupation* & \\
\hline $30<39$ & 9.2 & Allied Health & 24.2 \\
\hline $40<49$ & 25.7 & Dentist & 1.4 \\
\hline $50<59$ & 24.8 & GP & 5.3 \\
\hline $60<69$ & 32 & Specialist & 1.9 \\
\hline $70+$ & 8.3 & IHW & 6.8 \\
\hline & & Nurse & 54.6 \\
\hline Work Location & & Living Location & \\
\hline Very Remote & 24.8 & Live and work very remote & 42.4 \\
\hline Remote Town & 15.5 & FIFO live regional & 27.8 \\
\hline Regional Centre & 59.7 & FIFO live city & 13.2 \\
\hline Remote incentives & & Rural/Remote Placement & \\
\hline Yes & 59.5 & Yes & 27.5 \\
\hline No & 40.5 & No & 72.5 \\
\hline
\end{tabular}

*Variables do not add up to $100 \%$ as the values for 'other' are not presented. 


\section{Results}

Participants

The participants' characteristics for those that completed the demographics section are presented in Table 1. The sample was predominately female, there was a high representation of nurses, and $40 \%$ of participants had worked in a remote area for less than one year.

\section{Themes}

The thematic analysis identified themes that described why health professionals were attracted to work in remote regions. Next, a review of these themes revealed that some health professionals had not specifically chosen to work in a remote region. Rather, it was a consequence of circumstance, e.g. they already lived in the remote region; they were returning to the area where they were raised; or they moved to the remote area for their partner's work. These themes were removed, leaving eight themes that encapsulate why participants chose to work in remote regions that could be used to attract future workforces.

Table 2: Themes that encapsulated why health professionals work in remote regions and whether the experience met their expectations

\begin{tabular}{|c|c|}
\hline THEMES & TYPICAL QUOTES ABOUT EXPECTATION REALISATION \\
\hline $\begin{array}{l}\text { Adventure/Travel describes travelling } \\
\text { long distances and to unique areas. }\end{array}$ & $\begin{array}{l}\text { 'I would never have imagined being able to travel to some of the } \\
\text { places I have!' (QP151) } \\
\text { 'distance to travel to/from jobs or to assistance for evacs, I never } \\
\text { really understood the enormity of the job' (QP90) }\end{array}$ \\
\hline $\begin{array}{l}\text { Autonomy describes a level of independence, } \\
\text { free from external control. }\end{array}$ & $\begin{array}{l}\text { 'Autonomy can be great' (QP150) } \\
\text { 'there is less autonomy and more requirement to follow procedures } \\
\text { set from the city without any consultation' (QP24) }\end{array}$ \\
\hline $\begin{array}{l}\text { Geography describes the physical } \\
\text { environment. }\end{array}$ & $\begin{array}{l}\text { 'challenging most days and I love the country' (QP20) } \\
\text { 'I also didn't realise until moving to a remote region how limited } \\
\text { resources can be for work' (QP190) }\end{array}$ \\
\hline $\begin{array}{l}\text { Indigenous health means both the wellbeing } \\
\text { of individuals and the social, emotional and } \\
\text { cultural wellbeing of the Indigenous } \\
\text { community. }\end{array}$ & $\begin{array}{l}\text { 'it was as I expected, with a few curve balls as I was experiencing } \\
\text { the different cultures' (QP2) } \\
\text { 'Indigenous health is also challenging' (QP110) }\end{array}$ \\
\hline $\begin{array}{l}\text { Lifestyle describes the way in which a person } \\
\text { desires to live. }\end{array}$ & $\begin{array}{l}\text { 'did not expect that the lifestyle I have developed would be so } \\
\text { fulfilling and meaningful to me as a person' (QP45) } \\
\text { 'difficult to achieve work/life balance' (QP142) }\end{array}$ \\
\hline $\begin{array}{l}\text { Make a Difference describes an intrinsic } \\
\text { desire to improve the lives of clients. }\end{array}$ & $\begin{array}{l}\text { 'I am disappointed at times that I am not able to do more to help } \\
\text { people as some people don't want to be helped' (QP135) } \\
\text { 'I am often left wondering if we/I will ever make a difference' } \\
\text { (QP184). }\end{array}$ \\
\hline $\begin{array}{l}\text { Remuneration describes the financial benefits } \\
\text { that an employee receives from their employer. }\end{array}$ & $\begin{array}{l}\text { 'we can afford for my husband to stay home with the kids and } \\
\text { only parent has to work' (QP57) } \\
\text { 'better pay and conditions' (QP58) }\end{array}$ \\
\hline $\begin{array}{l}\text { Scope-of-practice describes working within } \\
\text { professional boundaries compatible within } \\
\text { their qualifications and skills. }\end{array}$ & $\begin{array}{l}\text { 'Enjoy working in a wide scope-of-practice'(QP5) } \\
\text { 'The work in remote regions is markedly different to that in metro } \\
\text { areas and was not what I expected. I have found the two clinical } \\
\text { areas vastly different and initially had to adapt' (QP45). }\end{array}$ \\
\hline
\end{tabular}


These eight themes were: adventure/travel, autonomy, lifestyle, geography, Indigenous health, making a difference, remuneration and scope-of-practice. Table 2 contains a description of these themes and some typical quotes about whether or not the experience met their expectations for each theme. The analysis revealed that the three most frequent themes that encapsulate why health professionals choose to work in remote regions were: lifestyle, scope-ofpractice and Indigenous health (Table 3).

Table 3: Themes describing why health professionals choose to work in remote regions $(n=216)$

\begin{tabular}{|lc|}
\hline THEMES & $\%^{*}$ \\
\hline Lifestyle & 18 \\
\hline Scope-of-practice & 17 \\
\hline Indigenous Health & 11 \\
\hline Adventure/Travel & 8 \\
\hline Make a Difference & 6 \\
\hline Remuneration & 4 \\
\hline Autonomy & 4 \\
\hline Geography & 1 \\
\hline
\end{tabular}

*This table does not add up to $100 \%$ as themes that did not imply 'choice' were removed (see study one methods section).

\section{Study two \\ Methods}

Study two identified the incentives that managers use to attract health professionals to remote regions through an examination of recruitment advertisements. Recruitment advertisements were collected from five recruitment websites between August 2013 and July 2015. These websites were:

- Western Australia Government (http://www.jobs.wa.gov.au)

- Northern Territory Government (https://jobs.nt.gov.au/Search.aspx)

- Queensland Government (https://smartjobs.qld.gov.au/jobtools)

- $\quad$ Seek (http://www.seek.com.au)

- CareerOne (http://careerone.com.au)

During this period, 3311 advertisements met the following inclusion criteria:

1. The position was in remote northern Australia (described previously)
2. The position involved contact with patients for treatment or to enable/assist patients to receive treatment; or the management of people who have contact with patients for treatment or to enable/assist patients to receive treatment

3. The position required a health-related qualification and/ or experience in a role that provided healthcare services.

The content analysis was conducted to systematically analyse the advertisements, enabling the written data to be coded and then counted. An a priori coding method used a checklist based on the themes identified in study one. The descriptive quantitative data analyses were conducted using the statistical software package SPSS22.

\section{Results}

The recruitment advertising contained content comparable with the themes identified by the current remote health professionals (Table 4). There was considerable variance in the frequency in which these themes were contained in the recruitment advertising. The three most frequently identified themes were remuneration, geography, then lifestyle and adventure/travel (both ranked third).

Remuneration was the theme most frequently used to attract health professionals to remote regions. Remuneration incentives were usually offered to nursing and medical professionals for the completion of a defined period of time in a remote location. For example, the Remote Area Nursing Incentive Package included isolation bonuses for one, two and three years of service; and the General Practice Rural Incentives Program offered bonuses for working in very remote areas for six months, and then annually with the amount increasing each year. The recruitment advertising sent a strong message to potential applicants about the remuneration on offer, and about areas of frequent turnover.

The analysis highlighted an observable difference in the style of the advertisements by recruitment agencies and health service organisations. It was only recruitment agencies that offered incentives like an opportunity to win a free iPAD for a successful referral, frequent flying points and impertinent calls to action, such as, 'Midwives are as HOT AS BURNT TOAST in Australia and we simply CANNOT get enough of them' and 'Calling Rural Superheroes ... To be successful you must be an all-round experienced generalist; fearless, flexible and ready to wear your red undies on the outside superhero style.'

Overall, there was a mix of realistic and enhanced descriptions of the geographical area, with few that described the challenges of working, living and maintaining professional 
Table 4: Themes that encapsulated why health professionals work in remote regions contained in the recruitment advertisements

\begin{tabular}{|c|c|}
\hline THEME & EXAMPLES OF THE CONTENT IN RECRUITMENT ADVERTISEMENTS \\
\hline Adventure/Travel & $\begin{array}{l}\text { 'Do you want to experience a bit of the Australian outback where the } \\
\text { most traffic you will have will be cattle and Kangaroos? Are you keen } \\
\text { for a well-paid adventure?' } \\
\text { 'We will offer you the experience and adventure of a lifetime' }\end{array}$ \\
\hline Autonomy & $\begin{array}{l}\text { 'You will be expected to work autonomously at times' } \\
\text { 'This is a relaxed and flexible role ... You see two patients per day and } \\
\text { if you finish with the patients early, you simply go home for the day. } \\
\text { Some of the staff choose to finish early and go fishing or goanna } \\
\text { hunting with the locals!' }\end{array}$ \\
\hline Geography & $\begin{array}{l}\text { 'It's rural Australia, so this is not for everyone. You will be isolated, } \\
\text { you will be hot! But the rewards outweigh the location' } \\
\text { 'This area has a sub-tropical climate and much of the areas you will } \\
\text { be travelling into are on unsealed roads. We are now approaching the } \\
\text { hot and humid season in the area' }\end{array}$ \\
\hline Indigenous Health & $\begin{array}{l}\text { 'Passionate about providing quality healthcare to Indigenous Australians' } \\
\text { 'You'll go home every day with a sense of accomplishment knowing that } \\
\text { your work is contributing to the wellbeing of Yolnu people' }\end{array}$ \\
\hline Lifestyle & $\begin{array}{l}\text { 'If you enjoy camping, adventure and an outdoor lifestyle, this is the place } \\
\text { for you' } \\
\text { 'bring your fishing rod, sunscreen and a good book for your days off. } \\
\text { There will be plenty of time to enjoy the island view!' }\end{array}$ \\
\hline Make a difference & $\begin{array}{l}\text { 'This is a once in a lifetime opportunity to make a difference' } \\
\text { 'Rural nursing is more than just your hours at work, it's being part of } \\
\text { a community and making a real difference in the relatively short time you } \\
\text { have' }\end{array}$ \\
\hline Remuneration & $\begin{array}{l}\text { 'The package - base salary }+\$ 200 \text { per week remote allowance + salary } \\
\text { sacrifice up to } \$ 16,000 \text {. You basically only have to pay for your food' } \\
\text { 'New Zealand Midwives wanted for cashed up Australian contracts in } 2015 \\
\text { "SHOW ME THE MIDWIVES" in } 2015 ! \text { ! We have clients ... begging us for more } \\
\text { midwives in } 2015 \text { - and do we have a deal for you!!' }\end{array}$ \\
\hline Scope-of-practice & $\begin{array}{l}\text { 'Educated and endorsed [...] in an advanced and expanded clinical role, } \\
\text { as set out in their Practice Scope' } \\
\text { 'Nurses with additional authorisations must apply to [the] Nursing } \\
\text { Scope-of-practice Committee to receive authority to practice prior to } \\
\text { being able to perform the duties associated with such an authorisation' }\end{array}$ \\
\hline
\end{tabular}


practice in unfavourable geographical conditions (e.g. climate, infrastructure and resources) (Table 4). Interestingly, autonomy is often reported as being one of the benefits of working in remote regions; however, few advertisements promoted 'autonomy' or 'working autonomously'. Some described aspects of the lifestyle, where health professionals could determine their daily activities perpetuating the image of the laid-back remote lifestyle. In addition, many emphasised aspects of travel/adventure that a rural lifestyle afforded, particularly outdoor activities such as rodeos, fishing and camping. There was a sense in many of the advertisements that the health professional had plenty of time to enjoy their remote geographic location with messages such as 'Your lifestyle is Your choice'.

The recruitment advertisements contained information for all of the themes identified in study one (Table 5). However, they were not identified in the same order of frequency; for example, lifestyle was the only one of the three most frequently reported themes by current health professionals that was also one of the three most frequently appearing themes in the recruitment advertisements. Also, scope-ofpractice was the fourth most frequent theme reported by health professionals and the least frequently reported theme in the recruitment advertisements. Similarly, remuneration was most frequently contained in recruitment advertising and the least reported theme for health professionals.

Table 5: Comparison of the themes from study one and study two

\begin{tabular}{|lcc|}
\hline THEME & $\begin{array}{c}\text { RECRUITMENT } \\
\text { ADVERTISEMENTS } \\
(\mathbf{N}=3311)\end{array}$ & $\begin{array}{c}\text { HEALTH } \\
\text { PROFESSIONALS } \\
(\mathbf{N}=216)\end{array}$ \\
\hline Adventure/Travel & $8 \%$ & $8 \%$ \\
\hline Autonomy & $2 \%$ & $4 \%$ \\
\hline Geography & $14 \%$ & $1 \%$ \\
\hline Indigenous Health & $6 \%$ & $11 \%$ \\
\hline Lifestyle & $8 \%$ & $18 \%$ \\
\hline Make a Difference & $6 \%$ & $6 \%$ \\
\hline Remuneration & $56 \%$ & $4 \%$ \\
\hline Scope-of-practice & $2 \%$ & $17 \%$ \\
\hline
\end{tabular}

In summary, these two studies contribute to our understanding about why health professionals choose to work in remote regions and the incentives for working in remote regions communicated through recruitment advertising. The findings revealed that recruitment advertisements contained information congruent with the themes that health professionals reported had attracted them to remote regions.

\section{Discussion}

The findings highlight how unrealistic expectations can form through recruitment advertisements. Recruitment advertisements not only seek to attract suitable applicants, they are where the employee's expectations and perceived obligations of the employer begin to form the psychological contract. In addition, they highlight disparities in the amount of attention given in advertising content to themes that the current health workforce did not report as influencing their decision. Most importantly, they revealed opportunities to better align recruitment practices, and provide insight into how unrealistic expectations can lead to breaches in the employee's psychological contract. Furthermore, as psychological contracts develop, unmet expectations, often derived from the recruitment process are noteworthy as these unwritten agreements influence psychological contract formation and ultimately retention. $[11,16]$ Hence, there are both theoretical and practical implications for managers, academics, and health services.

\section{Scope-of-Practice}

Many health professionals reported that working in remote regions provided an opportunity to broaden their scopeof-practice. This is consistent with the findings from other studies where remote health professionals enjoy the diversity and scope of remote health. [10,14] However, empirical evidence is needed to determine whether using scope-of-practice for workforce attraction translates into improvements in workforce retention. In particular, where ageing workforces are becoming more common in rural and remote regions, there are opportunities to explore the degree to which scope-of-practice impacts retention. For example, whether remote regions are more attractive to health professionals with extensive and broad clinical expertise because the scope-of-practice is rewarding or perhaps the skills and experience required necessitates many years of professional practice to have the scopeof-practice competence required in remote regions. Geographical isolation contributes further to this scenario as reduced access to medical assistance and vast distances further necessitate the need for experienced health professionals who can work within the full scope of their professional practice parameters. [24,25] Positive advances have been made in preparing health professionals for rural, remote and isolated practice with established pathways to expose and prepare university graduates for geographically remote work. [14,15] 


\section{Management practices}

The findings from this study suggest opportunities for managers to positively influence retention through psychological contract formation during the recruitment process. Firstly, managers contribute to the formation of perceptions about the position which develop during the attraction stage of the recruitment process (e.g. description of desired lifestyle, free accommodation). Next, during the recruitment and appointment process the manager creates expectations about incentives or rewards that remain unwritten, contributing to transactional psychological contract formation. For example, an applicant who is attracted to the lifestyle, (e.g. told they go fishing after work) may feel that the manager has breached their psychological contract if they find on arrival that they do not have access to a vehicle and that they are on-call most days, resulting in the desired lifestyle that attracted them unlikely to eventuate. After commencing, health professionals often described experiences where the job and organisational characteristics do not meet their expectations. [20,23] In geographically remote regions, voluntary turnover is costly and health professionals are not easily replaced which results in reduced access to health services for remote communities. [1] For organisations competing in a sector with global workforce shortages, it is difficult to attract health professionals to geographically remote regions whilst maintaining a sense of realism about the working conditions and environment. This is the dilemma of the contemporary health service manager.

Given that many health professionals described scope-ofpractice, lifestyle and Indigenous health most frequently as reasons for going to work in remote regions it follows that health services could focus their advertising on emphasising clinical skill development opportunities (scope-of-practice and Indigenous health) as well as realistic descriptions of geographically remote regions to contribute to the development of more reasonable psychological contracts. There are many geographically remote regions that offer a great outdoor lifestyle, with opportunities to develop professionally. Thus, the reality is rewarding. Empirical theorybased evidence provides insight into opportunities to build theory and inform practice. As such, this study proposes that transparent recruitment practices using incentives to attract health professionals that have previously attracted health professionals, improves the likelihood that they will stay long enough to appreciate these rewards.

This study was conducted in geographically remote regions of Australia; regions where remote communities are experiencing increasingly complex health challenges, and accessing the healthcare services provided by remote health professionals is critical. Given that managers are responsible for the recruitment of health professionals in these regions, it is imperative that managers consider the perspectives of current remote health workforces, when recruiting future workforces, particularly, in a sector with predicted global workforce shortages.

\section{Limitations}

The low response rate for the questionnaire means that caution should be used in applying these findings to other remote regions. In addition, it is possible that there was a self-selection bias for the questionnaire.

\section{Conclusion}

In conclusion, the findings suggest that the themes that describe why health professionals are attracted to remote regions and those that managers use to attract remote health professionals are comparable. Therefore, recruitment practices can significantly impact retention. Where managers use transparent recruitment processes, employees are less likely to form psychological contracts with unrealistic expectations. As a consequence, psychological contracts are less likely to negatively impact retention.

This study found that while recruitment advertisements are using appropriate content to attract health professionals working in remote regions, there is considerable scope for improvement so that attraction translates into improved retention. Hence, managers should focus on tailoring recruitment practices to attract future workforces based on what attracted their current workforce to improve workforce stability. In geographically remote regions, workforce stability reduces the financial and social costs of turnover and improves access to healthcare services for remote populations.

\section{Competing interests}

The author declares that he has no competing interests.

\section{References}

1. McKenzie FH. Attracting and retaining skilled and professional staff in remote locations of Australia. Rangeland Journal. 2011; 33(4):353-363.

2. Morell A, Kiem S, Millsteed M, Pollice A. Attraction, recruitment and distribution of health professionals in rural and remote Australia: early results of the Rural Health Professionals Program. Human Resources for Health. 2014;12(15).

3. Murray RB, Wronski I. When the tide goes out: health workforce in rural, remote and Indigenous communities. Med J Aust. 2006 185(1):37-38

4. Campbell J, Dussault G, Buchan J, Pozo-Martin F, Guerra Arias M, 
Leone $\mathrm{C}$, et al. A universal truth: no health without a workforce. Forum Report, Third Global Forum on Human Resources for Health, Recife, Brazil. Geneva: Global Health Workforce Alliance and World Health Organization; 2013.

5. World Health Organisation (WHO). Increasing access to health workers in remote and rural areas through improved retention 2010 (accessed 29 March 2017). Available from: http://www.who. int/hrh/retention/guidelines/en/

6. Garnett S, Coe K, Golebiowska K, Walsh H, Zander K, Guthridge S, et al. Attracting and keeping nursing professionals in an environment of chronic labour shortage: a study of mobility among nurses and midwives in the Northern Territory of Australia. Darwin: Charles Darwin University Press; 2008.

7. Campbell N, McAllister L, Eley D. The influence of motivation in recruitment and retention of rural and remote allied health professionals: a literature review (accessed 23 June 2017). Rural and Remote Health. 12(3):1900. (Online) 2012. Available from: http://www.rrh.org.au

8. Hunter E, Onnis L, Santhanam-Martin R, Skalicky J, Gynther B, Dyer $\mathrm{G}$. Beasts of burden or organised cooperation: the story of a mental health team in remote, Indigenous Australia. Australasian Psychiatry. 2013;21(6): 572-577.

9. Buykx P, Humphreys J, Wakerman J, Pashen D. Systematic review of effective retention incentives for health workers in rural and remote areas: towards evidence-based policy. Aust J Rural Health. 2010;18:102-109.

10. Onnis L, Pryce J. Health professionals working in remote Australia: a review of the literature. Asia Pacific Journal of Human Resources. 2016;54: 32-56.

11. McGrail MR, Wingrove PM, Petterson SM, Humphreys JS, Russell DJ, Bazemore AW. Measuring the attractiveness of rural communities in accounting for differences of rural primary care workforce supply (accessed 22 June 2017). Rural and Remote Health. (Internet) 2017;17:3925. Available: http://www.rrh.org.au/articles/ subviewnew.asp? ArticleID=3925(Accessed 22/06/2017)

12. Humphreys JS, McGrail MR, Joyce CM, Scott A, Kalb G. Who should receive recruitment and retention incentives? Improved targeting of rural doctors using medical workforce data. Aust J Rural Health. 2012;20(1): 3-10.

13. Campbell N, McAllister L, Eley D. The influence of motivation in recruitment and retention of rural and remote allied health professionals: a literature review. Rural and Remote Health. 2012;12:1900.

14. Hegney D, McCarthy A, Rogers-Clark C, Gorman D. Why nurses are attracted to rural and remote practice. Aust J Rural Health. 2002; 10(3):178-86.

15. Kent-Wilkinson A, Starr L, Dumanski S, Fleck J, LeFebvre A, Child A International nursing student exchange: rural and remote clinical experiences in Australia. Journal of Agromedicine. 2010;15(1): 58-65.

16. Knights JA, Kennedy BJ. Psychological contract violation: impacts on job satisfaction and organizational commitment among Australian senior public servants. Applied HRM Research. 2005; 10(2): 57-72.

17. Coyle-Shapiro J, Kessler I. Consequences of the Psychological Contract for the employment relationship: a large scale survey. Journal of Management Studies. 2000; 37(7):903-930.

18. Cullinane N, Dundon T. The psychological contract: a critical review. International Journal of Management Reviews. 2006; 8(2):113-29.

19. Australian Bureau of Statistics (ABS). ASGC Remoteness
Classification: Purpose and Use (Census Paper No. 03/01) (accessed 29 March 2017). ABS; Canberra: 2003. Available from: http://www. abs.gov.au/websitedbs/D3110122.nsf/0/f9c96fb635cce780ca256d 420005dc02/\$FILE/Remoteness_Paper_text_final.pdf

20. Evans J, Mathur A. The value of online surveys. Internet Research 2005;15(2):195-219.

21. Australian Medical Association (AMA). Rural Health Issues Survey 2007. Available from: http://staging.ama.com.au/ama-rural-healthissues-survey (Accessed 22/03/2016).

22. Rural Doctors Association of Australia (RDAA). Rural, Regional and Remote Medical Specialists Survey 2012 (accessed 29 March 2017). Available from: http://www.rdaa.com.au/Uploads/Documents/ FInal\%20(with\%20Updated\%20Logo)\%20RDAA\%20rural\%20 medical\%20specialist\%20survey_20121011030002.pdf

23. Onnis L, Dyer G. Maintaining hope: the intrinsic role of professiona support. The Journal of Mental Health Training, Education, and Practice. 2017;12(1):13-23.

24. Hegney D, McCarthy A, Rogers-Clark C, Gorman D. Retaining rura and remote area nurses. The Queensland, Australia experience. J Nursing Adm. 2002; 32(3):128-135.

25. Lenthall S, Wakerman J, Opie T, Dunn S, MacLeod M, Dollard M, et al. Nursing workforce in very remote Australia, characteristics and key issues. Aust J Rural Health. 2011;19(1):32-37. 